\title{
ESCRITORAS DE LA GENERACIÓN DEL CINCUENTA. CLAVES PARA UNA LECTURA POLÍTICA
}

\author{
Raquel Olea $\left({ }^{*}\right)$
}

\section{RESUMEN}

En la producción de la desnaturalización de la sumisión de las mujeres, inscrita históricamente en el orden de una sociedad eclesial-patriarcal, burguesa y hacendal que evidencia su desmoronamiento y su decadencia, la escritura de las mujeres de la Generación del 50 propone claves de lectura que se juegan en las relaciones que los textos establecen con: las políticas escriturales de su contemporaneidad, el contexto histórico-social global y chileno, con la relación de las mujeres con el poder y la política y con el existencialismo como sistema filosófico.

Frente a la hegemonía del discurso marxista que domina la interpretación de la época, el enunciado feminista lo privado también es político ofrece la clave discursiva de inteligibilidad de los discursos políticos que estos textos sostienen.

Palabras clave:

Generación - política - existencialismo - escritura - feminismo.

$\left.{ }^{*}\right)$ Dra. en Literatura. Universida J.W. Goethe, Frankurt, Alemania. Profesora titular, Facultad de Humanidades, Universidad de Santiago de Chile (USACh).

Artículo recibido el 27 de mayo de 2010. Aceptado por el Comité Editorial el 29 de septiembre de 2010.

Correo electrónico: raquelolea@vtr.net 


\begin{abstract}
In the production of denaturalization of women's submission, historically inscribed in the religious-patriarchal society, bourgeoise and landowning, which evidences its own fall and decadence, women's writing of the Generation of 1950, proposes reading clues that play in the relationships that texts establish with: contemporary writing policies, the historical and social context (global and local), with the relationship with power and politics, and Existentialism as a philosophical system. Facing the hegemony of the Marxist discourse that dominates the interpretation of the period, the Feminist dictum private sphere is political as well offers a discursive clue to make intelligible the political discourses that these texts support.
\end{abstract}

Keywords:

Generation - politic - existentialism - writing - feminism.

Para hacer posible una nueva inscripción crítica de la narrativa que las mujeres de la Generación del 50 produjeron, en su época -y quienes con posterioridad a los años sesenta siguieron publicando-, es necesario hacer converger algunas relaciones que sus textos enuncian con el contexto social y la tradición literaria chilena, como incluirlas en la noción de generación que legitimó esta producción en la historia de la literatura chilena. Releerlas en la actualidad requiere establecer las correspondencias o disidencias escriturales con su contemporaneidad, pensar las procedencias filosóficas e ideológicas del pensamiento que las anima, para establecer contigüidades, similitudes y distinciones entre sus escrituras.

Una pregunta fundamental anima este texto, ¿Qué política escritural y qué producciones de sentidos es posible construir en una lectura actualizada de esos textos? La o las respuestas haría posible inscribir legítimamente su escritura en un doble recorrido ya trazado y reconocido por la crítica, la de pertenecer a un corpus específico de problemas literarios y culturales, orientados a validar en la historia una producción de representaciones de sujeto femenino, no escritas desde otros lugares de enunciación, pero también la de inscribirlas en su diferencia. No se trataría de producir una tradición aparte, sino de explicitar recorridos particulares en el interior de la misma tradición que en relaciones de (dis)continuidad, (dis)tensiones y productividades alternas con los textos hegemónicos encuentran sus sentidos más propios. Me interesa abrir ciertos interrogantes estéticos, éticas y advertir sus singulares condiciones de producción y lectura.

\title{
UNA GENERACIÓN INVENTADA
}

Entre los veinticuatro autores que el escritor Enrique Lafourcade seleccionó en el año 1954 para realizar la Antología del nuevo cuento chileno, hay cinco mujeres: María Elena Gertner, Yolanda Gutiérrez, Pilar Larraín, Gloria Montaldo, Margarita Aguirre y María Eugenia Sanhueza. La antología Cuentos de la Generación del 50 que el mismo autor 
publicó en 1959, cinco años más tarde, ratifica a Margarita Aguirre y a María Elena Gertner, como las únicas autoras que -en estudios posteriores- han sido reconocidas como parte de la generación ${ }^{1}$. De ese modo, tanto Aguirre como Gertner son las autoras que la crítica hegemónica hace pertenecer a la Generación. Como criterio de selección Lafourcade argumentó consideraciones cronológicas, una de ellas afectaba a los autores -fechas de nacimiento- y otra a los textos -fechas de publicación-, además, señaló que en dichos criterios habría elementos estéticos y literarios que harían posible hablar y configurar una nueva generación, "diversas circunstancias permiten hablar de una nueva generación de escritores". Entre sus características destacó el carácter individualista y hermético de los autores, enfatizando que esta es "una generación abierta, sensible e inteligente. Todos los escritores que la integran conocen a fondo, o están en trance de conocer, la literatura contemporánea y la problemática fundamental de esa literatura". Destaca también que:

[...] Es una generación antirrevolucionaria. Su beligerancia si la hay, consiste en realizar a conciencia, y hasta sus extremas posibilidades creadoras, su obra. No escriben para combatir, negar, afirmar algo de orden social o histórico. Trabajan por rescatar del fondo de sí mismos un sentido, distinto para cada uno. Comprometidos profundamente con su oficio, cada uno de estos escritores se desentiende de todo aquello que vulnere su actividad (Lafourcade, 1954, pp. 14-15).

La mencionada antología desató polémica en la prensa de la época, descalificaciones, valoraciones y juicios críticos acerca de los modos de su concepción y realización, los que fueron componentes sabrosos de un revuelo del momento que a pesar de opiniones negativas, disensos y controversia, legitimó a esa generación.

Dice Margarita Aguirre: "Por supuesto que existió la Generación del 50. Y harto ruido que metió. La integraron los que fuimos seleccionados por Enrique Lafourcade [...] esta generación existió porque tuvo su inventor, Lafourcade". (Godoy, pp. 343-344). Sin embargo, Elisa Serrana ha dicho: "no sentía mayor conexión con ellas, convivíamos muy bien en la vida literaria de las ferias del libro, de giras y en los primeros programas de televisión, pero no sentíamos que fuéramos una generación [...]". (Revista Qué Pasa N² 207, Santiago de Chile, 10 de abril de 1975).

Las escritoras que no fueron incorporadas en la antología de Lafourcade (Marta Jara, Mercedes Valdivieso, Elisa Serrana, Elena Aldunate, Matilde Ladrón de Guevara), aunque cumplieran con las características señaladas por el antologador, han padecido un olvido que recientemente empieza a ser abandonado, por el hecho de ser leídas como un corpus de textos que se ha comenzado a denominar como Escritoras de la Generación del 50. Sus obras fueron publicadas por Zig-Zag en la década de 1960, y aún se encuentran en librerías de viejos en la calle San Diego de Santiago. Elisa Serrana ha sido reeditada por Editorial Andrés Bello en 2002 y un volumen titulado Obras selectas recupera la totalidad de su narrativa; Marta Jara ha sido publicada por Lom Ediciones; Mercedes Valdivieso por Editorial Cuarto Propio, y su libro La brecha ha sido

${ }^{1}$ Eduardo Godoy en su exhaustivo estudio de la Generación mantiene los mismos nombres. La Generación del 50 en Chile. Historia de un movimiento literario, Editorial La Noria, Santiago, 1992. 
calificado como la primera novela feminista por la crítica de los años noventa. Mérito o arbitrariedad del inventor, el problema invita a repensar, no sólo el invento, sino la parcialidad de las lecturas relativas a las significaciones de los textos. Sin embargo, lecturas actuales proponen reconsiderar a estas autoras y pensar su escritura junto con quienes fueron antologadas, no para ejercer una demanda de inclusión en el canon de Lafourcade, sino para constituir un corpus que legítimamente lea lo que de manera crítica no pudo considerarse, y así repensar el aporte de una literatura de anticipo con el fin de remover y combatir "algo del orden social e histórico", inscrito en los signos de una cultura masculina que no fue explícitamente elaborado por sus pares contemporáneos y que tuvo especiales resonancias contextuales.

El corpus de textos que se configura en la escritura de las mujeres del cincuenta -las excluidas y las incluidas- retorna para situarse en la historia literaria y abrir las restringidas miradas del "orden social e histórico" referido sólo a desigualdades de clases, a condicionamientos económicos y a otras problemáticas que, miradas desde la universalidad del sujeto, dejan fuera de su espectro de reflexión cuestiones culturales y un sentido de diferencia latentes en el contexto en relación con la heterogeneidad social, con las producciones de sujeto e identidades y con las problemáticas de género. Las escritoras del cincuenta proponen en su escritura la desnaturalización de la sumisión de la mujer, que la sitúan históricamente en el orden de una sociedad eclesial-patriarcal, burguesa y hacendal que evidencia su desmoronamiento y su decadencia. La teoría crítica feminista nos permite leer hoy en esos textos significaciones y sentidos culturales donde las mujeres inscriben, en el espíritu de una sociedad en crisis, serios interrogantes a la familia y a las jerarquías que condicionan sus vidas. Una política escritural situada en lo privado y en la intimidad, les hace posible abrir otras percepciones del orden dominante, potenciando interrogantes críticos al régimen estabilizado de lo femenino.

Si las antologías cumplen una importante función crítica, que anuncia lo nuevo y destaca autores promisorios, también sabemos que una antología es siempre una selección arbitraria que responde al criterio, al gusto y a las afinidades del antologador, que no puede -nunca sucede- satisfacer todas las demandas de la lectura. Sin embargo, los avances de la crítica, los nuevos y distintos modos de leer y de relacionar la literatura con su tiempo y con la actualidad nos llama a volver a abrir viejos libros, con la seguridad que algo se ha quedado oculto en ellos, aguardando el momento de nuevas miradas que puedan decir lo que antes no pudo verse. Hay textos que habiendo sido excluidos del canon de su época, resultan iluminadores para producir anticipaciones y proyecciones de situaciones literarias y culturales de distinta índole, algo así como anticipos de una innovación que sólo puede reconocerse más tarde. Al escribir experiencias y existencias femeninas singulares, aisladas, desconectadas de afuera, esta narrativa da cuenta de una situación cultural que busca producir subjetividades en crisis con las normativas de dominio y control, otras que aquellas reconfirmadas en las escrituras dominantes. Estrategias discursivas y lenguajes que hoy nos parecen pertinentes a hábitos y comportamientos aceptados y recurrentes, entonces significaron aperturas y rupturas a reglamentos y convenciones que parecían inamovibles. 
Me hago la pregunta, ¿qué hizo posible esta producción escritural? Los textos a que me refiero escribieron representaciones de existencias que interrogaron la ley de la subordinación femenina, interrumpiendo el curso del orden sustentado en instituciones tan incuestionadas como la familia, el poder de la Iglesia católica o los dispositivos reguladores de la sexualidad y los géneros.

Pienso hoy la narrativa escrita por las mujeres de la Generación del 50 como un corpus de textos, no busco producir autorías individualmente redimensionadas, sino poner en escena mundos narrativos con una propiedad que emerge de nuevos posicionamientos de sujeto y de nuevas situaciones de enunciación. Estos textos, además de cumplir con las características literarias y generacionales asignadas al grupo, fueron ampliamente leídos en su época, criticados en la prensa, reeditados y vendidos exitosamente; sin embargo, el hecho de haber permanecido fuera de la recepción de la crítica académica -que entonces sí tenía el poder de establecer el valor de los textos- los marginó de la historia y del ámbito de los estudios literarios, provocando su paulatino desaparecimiento de la memoria literaria de Chile. Dicho corpus merece relecturas. Su productividad no sólo amplía la significación otorgada a la generación, sino que ingresa a la historia literaria la escritura de una sujeto social que desde su particular condición enunciativa produce una diferencia de lenguajes y de modos de representación que la diferencia y distingue de sus contemporáneos varones. Las nuevas lecturas abren los textos a intensidades no evaluables por la crítica de su tiempo, pero también a aquello que por haber estado fuera de los órdenes imaginarios de su época no pudo ser mirado por los lectores o no se le otorgó valor de transformación: anticipos de lenguajes, de problemas relacionales, formas de resistencias a las hegemonías, nombramientos desplazados, emergen en lecturas actuales como datos relevantes para llenar vacíos e historizar un recorrido que da continuidad a modos de enunciar y validar experiencias de género.

Es por ello que no me propongo ingresar a una polémica -algo estéril- que cuestione el concepto de generación o la formación del canon como representación de determinados poderes: sociales, ideológicos, políticos o de género, aun sabiéndola válida, más bien me interesa repensar una producción que, como signo de un tiempo de significativos cambios políticos y culturales, da lugar en los lenguajes estéticos y literarios a un campo de problemas propios de la subjetividad femenina, en la multiplicidad de sus dimensiones, haciendo posible su ingreso al orden de las representaciones simbólicas desde una narrativa que sume sus particularidades en situaciones expresadas colectivamente. Las escrituras de la Generación del 50, abren el campo literario a voces narrativas que como un coro rompe el monólogo patriarcal para escenificar colectivamente el lenguaje de un nombramiento de cuerpo y género femenino. Si el corpus de novelas escritas por mujeres en la Generación del 50 comparte con sus pares masculinos malestares e interrogantes comunes a una época de transición y cambios en la sociedad chilena, constituye, simultáneamente, un nuevo lugar de enunciación que legitima ficciones y saberes de género, de lenguajes otros y de experiencias privadas e íntimas, de escenas corporales nombradas desde un yo que se autorrepresenta de un modo particular y rupturista. La política del texto podría resumirse en el anuncio de una sujeto que surge del silencio para autoconstituirse con voz y autonomía. Un 
lenguaje incardinado que irrumpe en el campo literario como una interrupción del guión del gran relato de género que fija a la mujer en la familia. Cuerpos y lenguajes de deseos y experiencias revocadas de los dominios del padre, emergen para enunciarse en una sujeto posicionada en su lenguaje.

Tres coordenadas me parecen pertinentes y válidas para elaborar la política textual que emerge del corpus mencionado:

i) El contexto histórico social de Chile, reconocido por sus pares masculinos como expresión de una crisis mundial y nacional, producto de posguerra en el primer caso, y de una época de cambios sociales y económicos, en el segundo, configura a la "generación" en su conjunto.

ii) La relación de las mujeres con el poder y la política, refiere la situación de las mujeres en el espacio público, como sujetos de ciudadanía, posterior al logro del voto pleno.

iii) El existencialismo como sistema filosófico, propone la existencia como precedencia de la esencia, construye un sujeto sin fe, lanzado a un mundo hostil, entregado a su propia soledad y angustia.

\section{SOCIEDAD EN CRISIS Y CAMBIO SOCIAL}

Desde finales de la década del treinta, hasta fines del cincuenta, el Partido Radical fue el partido unitario más fuerte y popular de Chile. Pedro Aguirre Cerda, Juan Antonio Ríos y Gabriel González Videla gobernaron desde 1938 hasta 1952. Los radicales, representantes del pensamiento laico y de la clase media en ascenso, buscaron equilibrar intereses sociales en conflicto, pero finalmente su habilidad para hacer coaliciones se les volvió insuficiente para mantener el poder; en 1952, los electores votaron al populista y exdictador Carlos Ibáñez y, en 1958, llegó a la presidencia el independiente de derecha, Jorge Alessandri. Este recorrido da cuenta de un período de incertidumbre social que enfatiza la pugna entre las posiciones laicas, representantes de la igualdad y la justicia social y el pensamiento católico y conservador, representante de las viejas estructuras y los privilegios de clase. Los vaivenes políticos señalan una época; por una parte, dan cuenta de una amenaza para la permanencia de las tradiciones y sus formas de organización de la vida y las relaciones sociales, bajo el signo de las jerarquías de clase y género; y por otra, enseña que estas deberían, ahora, aprender a coexistir con algunas resistencias, rechazos y deseos de modificación de ese paradigma, lo que significa una pérdida de hegemonía de la oligarquía terrateniente. La hacienda seguía siendo la institución organizadora del régimen de vida de los sectores agrarios y rurales, pero ahora debe coexistir con las modificaciones que trae la modernización, lo que significa una pérdida de hegemonía por cuanto la visión feudal y católica del mundo que se construía desde ese reducto de poder comienza a ser lenta, pero efectivamente intervenida, por efectos de la industrialización del país. Entre las acciones más destacadas de los gobiernos radicales está el haber fundado la Corporación de Fomento de la Producción (CORFO), institución impulsora de la industrialización del país; y haber dado lugar al ascenso de una nueva clase social que adhería -cada vez más y con más ahínco y convicciones- a la necesidad de construir la igualdad y la justicia social en un país con altos índices de analfabetismo, 
mortalidad infantil y pobreza. El rechazo e intervención del antiguo orden tenía también sus cómplices en los sectores jóvenes de antiguas familias hacendales, que se mostraban dispuestos a asociarse con la nueva clase económica, configurando una nueva burguesía urbana que se reconocía moderna y cosmopolita, que era crítica al poder de la Iglesia católica, más abierta a la diversidad social, que constituía una mezcla de modernidad y tradición, pero que en muchos aspectos se alejaba de las viejas costumbres morales. Esta nueva burguesía influida por sus viajes a Europa y sus lecturas de escritores y filósofos contemporáneos, no podía ya identificarse con formas de vida anticuadas y restrictivas. En esas circunstancias, la élite terrateniente se vio obligada a aceptar, de mala gana, a quienes antes habían estado marginados de un mundo que a ellos les parecía naturalmente ordenado. Siúticos y rotos comenzaron a ingresar a formas de sociabilidad antes exclusivas de unos pocos y excluyentes de todo lo otro. La sociedad chilena empezaba a ser más diversa y, como rasgo de modernidad inédita, se señala la creciente participación de mujeres en las profesiones, las artes e incluso en la vida pública.

La clase media educada comienza a hacer sentir su valor sobre una oligarquía atrasada y retrógrada en su pensamiento. El desarrollo de la administración pública y la ampliación de la educación los sitúa como ciudadanos atentos y participantes de las disputas de poder, que antes estuvo, casi por derecho natural, en manos de la oligarquía terrateniente. Después de la elección de González Videla, la situación del país se hace más crítica, lo que coincide con el fin de la Segunda Guerra Mundial. Asimismo, el ascenso de la votación del Partido Comunista y luego la traición a este del gobierno de González Videla, agudiza la percepción de un cambio cultural irreversible. El orden social tradicional tiene en este período un quiebre en lo más profundo de su legitimidad social y cultural.

Por otra parte, los gobiernos radicales tampoco habían logrado satisfacer sus promesas. En 1964, Chile tenía aproximadamente 8.000.000 de habitantes (Simon Collier-William F. Sater, p. 221).

Losjóvenes escritores, en su mayoría de origen burgués, y particularmente las escritoras -influidas por el feminismo europeo y norteamericano-, se sentían representantes de una nueva concepción de la mujer y, por tanto, rechazaban la sumisión y dependencia del régimen masculino de los géneros, estaban en la encrucijada de padecer la tensión entre adherir a lo nuevo y simultáneamente participar de un mundo caduco. Su necesidad fue la de distanciarse de las tradiciones vigentes: tanto de la tradición literaria estancada en el costumbrismo, de la familia como espacio de restricción y castración, de la ideología burguesa nacional desprestigiada en su provincianismo y, en general, de las determinantes de un orden social que, en explícito desplome, no podía interpretarlos.

Al clima interno de inestabilidad se sumaba el espíritu de escepticismo dejado por el fin de la Segunda Guerra Mundial. Escepticismo, angustia y sensación de inutilidad de los proyectos políticos, se vivieron como signos del malestar en la cultura de esos tiempos. Sus textos fueron la expresión de esa desazón que abarcaba lo social y lo moral. 
Los cambios sociales y los efectos de la pérdida del orden representado en el aferramiento de la oligarquía a sus feudos y derechos sobre la tierra y los cuerpos, otorgaron a estos escritores rebeldes y a su propio lugar de origen, preciados materiales para enunciar su resistencia y desprecio a la herencia familiar. Claudio Giaconi, promisorio escritor de la generación lo dice así:

No aceptábamos la vida como se presentaba: queríamos mejorarla, transformarla, pero sólo ofrecíamos los problemas [...] Todo nos parecía corrupto, sospechoso, desagradable, feo. Como individuos éramos típicos outsiders [...] En lo político -que duda cabe- éramos radicalmente escépticos (García-Corales, p. 314).

José Donoso escribió de manera magistral -desde sus primeros cuentos y a lo largo de toda su obra- la sociedad chilena en sus cruces de represiones y deseos, de clase y clasismo, de mezcla y heterogeneidades ocultas, enfatizando la decadencia de la burguesía. Su escritura despliega, quizás, la crítica más aguda e implacable a los dispositivos morales, sexuales y culturales de control llevados a cabo por la clase dominante de una sociedad dependiente, insegura y frágil en sus deseos de distinguirse de aquello que pudiera considerarse la identidad local; su desmoronamiento lo hace recurrir a la cita del grotesco y el esperpento para expresar con mayor nitidez su proyecto narrativo: la máscara, la inversión, el travestimiento, la carnavalización del mundo, serán algunas de los signos con que Donoso intensifica la representación de la decadencia del orden de la burguesía chilena.

Se ha mencionado que a la Generación del 50 debe la literatura chilena su definitivo ingreso a la contemporaneidad narrativa, incorporando en el relato técnicas que abren el texto a una multiespacialidad, a nuevas formas de experienciar la temporalidad, a la fragmentación del narrador. Las lecturas de Franz Kafka, James Joyce, Virginia Woolf y William Faulkner, los llevan a explorar modalidades narrativas abiertas a la multiplicación de voces narrativas, a quiebres en la causalidad del relato y la linealidad temporal, develando en una pluralidad de registros de hablas -conscientes e inconscientes- los énfasis de formas de escenificación del fin de una época, lo que acentúa los rasgos de una sociedad que nunca estuvo en la cima de nada ni alcanzó gloria alguna.

Las escrituras de las mujeres hicieron lo propio, sumándose al "espíritu de la época", pero se situaron en un recodo de experiencias características de su condición de género, donde la observación y la fina percepción del mundo que habitaban las llevaría a producir una escritura de develamiento de las naturalizaciones del poder masculino; deslegitimado en su significación social, hablan el mundo femenino del "de eso no se habla", al que otros textos no alcanzan a dar lugar. Escribirán doblemente el silencio y lo silenciado en un solo pliegue. Adentrada en el conocimiento emanado de la experiencia, la narrativa nombra lo inaceptable como precio pagado por los cuerpos, para sostener las exigencias de un orden que obliga a la sujeción, la renuncia y la mutilación del propio deseo; un matrimonio conveniente no podía ya ser un camino deseable para plenificar la existencia. La experiencia de falta de poder, de decisión y de elección de la existencia se revertirá en el motor de un deseo aún vago, no formulado, pero que pulsa y moviliza en otra dirección que el del plan familiar. 


\section{EXISTENCIALISMO Y FEMINISMO}

El reconocimiento de la influencia del existencialismo en los autores y autoras de la generación es amplio, así lo declaran muchos de ellos: "En aquel tiempo mis lecturas favoritas eran sobre todo el existencialismo. Yo creo que todos lo leíamos para aplaudirlo o denostarlo [...] leíamos poco a los chilenos y, en todo caso para anotar las diferencias. Nunca seré un Latorre, jamás un Luis Durán", dice Margarita Aguirre (Godoy, p. 344). Por su parte, Jorge Edwards, aclara: “La gran moda europea era el existencialismo [...] Sartre era una especie de sarampión, nos contagiaba a todos. Habíamos leído El muro, La náusea, Qué es la literatura, que nos influyó mucho" (Godoy, p. 351).

Las escritoras marcan su diferencia sumando a estas lecturas no sólo el pensamiento de Simone de Beauvoir, sino también sus novelas y cuentos, las que junto a otras autoras francesas como Francoise Sagan tienen con sus textos relaciones de intertextualidad; sus personajes femeninos hablan de sus lecturas existencialistas y se refieren al feminismo como una posición y un pensamiento que las seduce y las sitúa en el lugar de mujeres que desean y se arriesgan a las formas de emancipación que prometen otros contextos. Tanto el existencialismo de Sartre como el de Simone de Beauvoir ofrecen a los escritores y escritoras conceptos y categorías de interpretación de la vida en una sociedad que se ha vuelto ininteligible. El ser humano -hombres y mujeresdebe hacerse a sí mismo, no hay esencia que los trascienda. Se empieza por no ser nada, dice Sartre, así se es responsable para sí mismo, dueño de su elección. Esto, según él filósofo, permite comprender la angustia, el desamparo de estar en un mundo donde el compromiso con la propia existencia viene de la imposibilidad de escapar al sentimiento de su total y profunda responsabilidad. La crítica más tradicional de la época desata una polémica en cuanto al valor del existencialismo, en la literatura de la generación, señalando su negatividad y su no correspondencia con la sociedad chilena: ambiente pagano, materialismo, sordidez, nihilismo, desesperanza (Godoy, p. 203). Sin embargo, el existencialismo tiene un doble potencial para las escritoras; aceptar el sinsentido de una vida de sometimiento y falta de libertad implica reconocerse en una pertenencia de época, pero del mismo modo su conjunción con el feminismo significa una promesa de liberación y elección del propio destino. Por ello, las narraciones se sitúan en la tensión entre deseo de salir de un mundo que obliga a cumplir un mandato que las hace ser lo que una mujer debe ser y la (im)posibilidad de la elección de hacerse a sí mismas. La afirmación de Simone de Beauvoir, "no se nace mujer", opera como causa para pensar las existencias que los textos relatan y constituye la base de gran parte del corpus de la narrativa escrita por mujeres en la generación; escribir el tedio y la angustia, la incertidumbre y la (no) elección. Es en el modelo de la pregunta existencialista de Beauvoir relativa a la condición de la mujer donde las escritoras se sitúan para escribir existencias femeninas dominadas por el vacío existencial, el tedio, la falta de elección, el miedo al riesgo y a la libertad a que el orden patriarcal las ha sometido, dejándolas sumidas en la única expectativa posible, la náusea que el existencialismo tan bien ha escrito.

El eco de un deseo aún no formulable se enuncia desde un malestar en el cuerpo que dispone la necesidad de producción de un lenguaje que se haga cargo de esa 
experiencia; malestar de género que se traduce en la voluntad de nombrarse en esas formas de existencia, de producir en la escritura su representación simbólica, tal como lo señala de Beauvoir.

La búsqueda de la libertad como bien irrenunciable, los costos de la facultad de elegir, la acción como fundamento de la política son algunos de los efectos de la influencia de los textos de Simone de Beauvoir para afirmar un proyecto de escritura feminista. Abordar desde estas categorías el corpus de autoras tratadas, posibilita leerlo más allá de logros o fracasos existenciales con que cada texto connote a sus protagonistas y narradoras.

\section{EL SILENCIO FEMINISTA}

La lucha por obtener el derecho a votar en las elecciones municipales y presidenciales, había movilizado, en las décadas del treinta y del cuarenta, organizaciones, federaciones, medios de comunicación, partidos políticos y un amplio circuito de coordinaciones de mujeres creando una institucionalidad política que hizo posible realizar alianzas y crear movimiento social para escenificar una gran campaña pública sufragista. $L a$ mujer nueva, fue el órgano de prensa del Movimiento pro Emancipación de la Mujer Chilena (MEMCH), fundado en 1936 y refundado durante la dictadura militar de 1973 como señal de (dis)continuidad y memoria de la lucha por la liberación de las mujeres). En varios aspectos este había expresado una clara conciencia feminista con fundamentos en la política social.

Posteriormente a este período se produce en la década del cincuenta y sesenta un repliegue, que Julieta Kirkwood nombró como el silencio feminista (Kirkwood, pp. 159181). La autora se sorprende al constatar "que en momentos sociopolíticos de auge y profundización democrática no apareciera demanda femenina alguna -por ningún sector social" - (Kirkwood, p. 160) entendiéndolo como estrategia del proyecto de liberación global, que de ese modo busca evitar debilitamiento en la lucha ideológica. Otros temas, otras dudas, otras reivindicaciones sólo desviarían la lucha del objetivo central; políticamente "no se acepta incorporar demandas femeninas (planificación familiar) en los pliegos sindicales; se plantea explícitamente cuáles han de ser los temas válidos y prioritarios para la liberación global. Y, dentro de estos temas, la mujer quedó subordinada" (Kirkwood, p. 161) (el destacado es mío). La lucha que se reconoce es la lucha de clases. La izquierda política no tiene diálogo con las mujeres y en este punto es profundamente reaccionaria, no es sólo que la mujer deba esperar la emancipación de clase, sino que no desea "que la mujer abandone su lugar en el hogar y si es que sale a trabajar las labores de casa siguen estando en sus manos" (Kirkwood, p. 165). La subordinación de las mujeres a la que Kirkwood se refiere habla de una desprotección pública de estas. Sin espacios de representación como sujeto social, sin organizaciones, con escasos derechos laborales y de salud, sin derechos culturales ni comunicacionales, sin lugares de enunciación, para elaborar discursos y demandas, las mujeres quedan al arbitrio del orden tradicional de género que no sólo aparece naturalizado, sino que nadie cuestiona y que es avalado por el sistema jurídico y por la moral dominante sostenida por la Iglesia católica. Sin palabras para expresar una violencia simbólica 
(Bourdieu, p. 51) constituyente de las sociedades y las culturas patriarcales, la mujer está ahí para cumplir el destino de su naturaleza reproductiva y su sumisión a la ley del padre en el destino de esposa de Él y madre de los hijos de Él. La ausencia de discursos emancipadores es aprovechada por el poder masculino para construir el valor de la pareja como unidad social, a la vez que enfatiza la inhabilidad de las mujeres para tareas y trabajos que las distancien de los espacios del cuidado de otros y de lo concerniente al mundo doméstico. Estos discursos sumen a las mujeres en un percepción debilitada de sí mismas, en una vida de soledad, de mudez, de renuncia y aceptación de un destino inamovible, junto a una conciencia melancólica, autocastigadora que la reconfirma en la construcción masculina del "eterno femenino" (Beauvoir), poseído por la histeria que se cumple en el deseo del otro y no en el propio. La identidad posible y reconocida es la maternidad. La conciencia lúcida de esta condición y la voluntad política de su transformación es la materia narrativa del corpus de textos escritos por mujeres. Este gesto tiene particular relevancia si lo comprendemos dentro del vacío de acción política. Julieta Kirkwood, al reflexionar sobre el período del silencio, señala que incluso "en el sector de mujeres políticas conscientes se tenía la sensación de que no existía el problema femenino. Se aceptaba que tal vez antes, remotamente, fuese cierta la subordinación, pero que el problema mismo de la igualdad entre los sexos sólo dependía de cada una". La experiencia, sin embargo, de constatar en la historia familiar y en la propia las deficiencias de discurso, provoca a las escritoras a concentrar su talento narrativo en construir los efectos del habitus de género (Bourdieu, 1988), en una prosa abierta a nombrar(se) y representar(se) desde una sujeto femenina.

\section{EXISTENCIAS FEMENINAS}

En el descampado nacional relativo a discursos feministas las narradoras hablan la soledad, el tedio, el desamparo frente al compromiso existencial. María Elena Gertner en La mujer de sal, Margarita Aguirre en La culpa, o Elisa Serrana en Una o en Chilena, casada, sin profesión representan mujeres cautivas en lo que odian: la institución familiar. Marta Jara, en Surazo, trabaja esta problemática en ambientes rurales y regionales, sus cuentos hablan la sumisión y el debate interno de mujeres campesinas que entre el deseo y la culpa intentan habilitar para sí espacios de libertad.

La salida del orden se paga costosamente. Los textos narran un adentro solitario, sin afuera social, sin organizaciones ni discursos que funcionen como soporte o correlato político tendientes a favorecer otros proyectos de vida. Los cambios sociales están organizados desde las ideologías de izquierda dominante; la necesidad de escenificar lo múltiple y heterogéneo de lo femenino las lleva a permanecer en lo privado e íntimo, como una forma de nombrarse y establecerse desde una diferencia con lo masculino. Podría decirse que si las protagonistas no logran -del todo- construir su propio deseo, el espacio se ha abierto en el interrogante favorecido por la escritura que al ser enunciada desde una sujeto mujer no sólo relata existencias menores, resta de lo masculino, sino que las identificaciones entre las voces del texto conducen a otro espacio, aunque este aún se mantenga en el registro de lo secreto. Los textos abundan en la producción de diarios de vida, cartas no enviadas, proyectos de escrituras 
varias, que hacen emerger un habla que devela aquello depositado en el cuerpo, el secreto silenciosamente guardado -preñez sin marido, rechazo a la maternidad y la virginidad, aborto, adulterio- que ocultado por el poder encuentra en la trama del relato algún modo de escenificación, de develamiento, dando cuenta de los distintos registros de habla femenina: habla del cuerpo como depósito del poder, habla del castigo y el estigma.

Esta narrativa, encerrada en el espacio dominante de la casa familiar, escribe el cerco a que el orden burgués condena a las mujeres; atrapadas en su condición de burguesas, ajenas al proyecto global de cambio social escriben existencias femeninas asoladas, pero aún sin integración a un afuera que contenga sus demandas.

En Islas en la ciudad los destinos femeninos parecen jugarse en la sala de la casa de Carolina, donde ella, seductora anfitriona, habla de arte en conversaciones privadas con bohemios, artistas y diletantes, manifiesta su inquietud de escribir y salir del dominio del marido; es en la cama de la garçonnière de Mauricio donde Blanca conoce el sexo, allí puede develar su secreto y su miedo a enfrentarse a lo que no desea, es en la pieza oscura donde la madre de Blanca mastica su vacío, es en la soledad del cuerpo expuesto a la función materna donde las mujeres padecen una condición sin puerta de escape.

Espacios mínimamente abiertos, hablan de un afuera aún inhabitable para las mujeres. Desde esos lugares se avizora la posibilidad de lo nuevo, Blanca observa por las cortinas de su casa lo que sucede en ese espacio que representa para ella un mundo otro, un atisbo de amor lésbico se percibe en la admiración de Blanca por Carolina, ambas de distinta manera son víctimas de su imposibilidad de elegir, por ello todo vuelve al orden al final de la novela.

La novela La culpa de Margarita Aguirre, constituye un caso ejemplar para nombrar lo no nombrado de un orden donde el cuerpo de las mujeres funciona como espacio de registro familiar -en ese cuerpo debe cumplirse y escribirse la ley, su (des)obediencia regula la sexualidad al servicio del matrimonio y la procreación de hijos, que ingresan a la genealogía del padre-. Vigilado por la institucionalidad de la iglesia y el sistema jurídico; el cuerpo de la mujer debe responder a la ordenanza y reglamento de género (Butler, 2006, pp. 68-88). El cuerpo habla al silencio y si comparece es porque una falta se ha instalado ahí. Un falta que lo conducirá al ocultamiento, al claustro o a la ignominia, finalmente al olvido y al destierro de la sociedad. En La culpa, la madre, Carolina, no puede sino ser fiel a este orden, sin injerencia ni incidencia en el ejercicio del poder del padre, su destino consiste en colaborar; sin palabra con lo que odia, sólo le resta enfermar o enloquecer (Kofman, p. 57). Los hijos, de distinta manera, cumplen el sino inamovible. Melania, la niña violada, sin siquiera llegar a saber de su cuerpo, es el agente que desata la catástrofe familiar al concebir un guacho, por lo que ambos deben ser expulsados, señalando que aquello que rige para el hijo del patrón -procrear fuera de la ley, en el cuerpo de la mujer pobre- no rige para la hija; acallada, sin voz, no es oída porque no ha tenido aún acceso a la palabra; su inocencia y su condición de víctima no la salva, ni la preserva del estigma que obliga al ocultamiento y negación de su existencia. Sin 
derecho a ser nombrada y recordada, como muerta (en vida) pierde todos sus derechos, incluso el patrimonial. Sometida a una existencia fuera del orden de su clase, Melania se transforma en una expósita, a quien, muchos años después su sobrina Marta intenta recuperar del olvido, pero Marta también ha salido del orden familiar, abriendo su existencia a la mezcla con los otros, la nueva clase, "los rotos", orientándose a los nuevos planteamientos ideológicos de cambio e igualdad social, Marta con una vida heterogénea y plural no tiene cabida en los cambios sociales que se anuncian, porque no puede ofrecer nada, aunque continúa la tradición de la ruptura iniciada por Melania, fundando una genealogía de mujeres perdidas, madres de hijos sin padre, debe pagar con su vida; si ha intentado una elección esta la ha conducido a la destrucción, su existencia ha sido tan ominosa como la de su tía. No hay destino para ella. Ambas han parido un guacho, y ambas escriben su historia; la palabra también ocultada como su cuerpo, registra, constituye y da cuenta de otros saberes desde otro sujeto; saberes del secreto guardado en la escritura muda, testimonio de un cuerpo sin existencia.

Secreto de la escritura para nombrar el secreto significado en un silencio enterrado y encerrado en el cuerpo, para siempre. Margarita Aguirre había escrito en su primer libro Cuaderno de una muchacha muda, "Hay palabras que me gusta recordar hasta desgastarlas [...] Palabras que acompañan [...] querría que fueran sólo mías, que nadie las dijera nunca" (p. 13), en un gesto simbólico de apropiación del gesto y del particular sentido que la escritura les otorga.

Es Mercedes Valdivieso, en su novela La brecha -calificada en la década de 1990 como la primera novela feminista-, quien señala una torsión al destino de las mujeres. Sin dejar de ingresar al deber ser histórico, la protagonista -anónima representante de una actitud de género- asume otro destino, rompe el habitus, decide elegir aunque lo nuevo le sea desconocido y vago, sin importar los efectos ni el desprestigio, la narración produce otros "efectos de feminidad" (Cixous, p. 61) por el emprendimiento de una acción de políticas corporales, como el divorcio, el aborto, una segunda pareja y el ingreso al mundo del trabajo, entre otras. Estas acciones constituyen disidencias de las morales familiares y de las obediencias patriarcales, que abren un nuevo destino femenino, otro hacerse mujer, inaugurando otra ley y otro deseo.

Mujeres burguesas, las escritoras de la Generación del 50 escribieron burguesamente, constituyendo un discurso particular en el mismo tiempo y espacio de su generación, inscribiendo, frente a sus pares varones, una diferencia radical en la construcción del mundo narrado.

Desde el lugar de las esposas y madres de muchos hijos, educadas cristianamente y observantes católicas, se adentraron en la producción de heterogeneidad femenina para emprender una salida hacia otro lugar: a la bohemia, a la aventura amorosa, y a veces -o casi siempre- al reconocimiento de la (im)posible voluntad política de una transformación cultural. En La derrota de María Elena Gertner, Trinidad desciende socialmente, pero el conocimiento de la ciudad, la calle, el trabajo y la pobreza humillante le abre un nuevo hábitat que hace posible relacionarse con el deseo por un hombre de inferior condición, que le mostrará el placer antes prohibido. Aunque 
Trinidad permanece melancólicamente apegada a su pasado, la percepción de sí misma se modifica y se advierte en la pérdida de un bien que ya no desea. El desplome de clase la condiciona a su rechazo y le permite relacionarse con su cuerpo como agente de procesos de individuación necesarios para la constitución de una sujeto moderna.

Las representaciones femeninas de la escritura se sitúan en el entremedio de un pasado que las expulsa y una "utopía vaga" aún informulable, como señalara Julieta Kirkwood. En ese intersticio de lenguaje se juega la escritura, al margen del campo del poder social que opera las transformaciones generales sin nombrar las diferencias.

Las perspectivas actuales de lectura, heterogéneas y pluralistas, implican un trastocamiento de los signos de clase y género, que destituye los mitos que en su época impidieron valorar estos textos en su dimensión política. La miopía universalizante dejó pasar, sin leer, la política escritural de una diferencia que pudo hacer -junto al feminismo existencialista- de la crisis local enunciada por la generación una narrativa de desocultamiento de un excedente situado en la diferencia de género. Escribir desde lo privado y la intimidad produjo una nueva conciencia (feminista) que en el revés del poder condujo a una acción transformadora realizada por la acción de devenir una sujeto en el lenguaje. Más allá de la ciudadanía de derechos, las escritoras del cincuenta transitaron desde una negación de sujeto a la producción de una subjetividad en abierto despliegue de pensamiento y palabra. Los espacios de la intimidad se abrieron en estos textos para destituir la estricta separación entre lo privado y lo público y dar las primeras señas de un enunciado que ha movilizado organización y acciones políticas de las mujeres, "lo privado es político".

En un contexto de cambios sociales dominados por los proyectos de revoluciones globales, las revoluciones en la subjetividad no fueron acogidas, como si lo privado ocurriera sin tener incidencia en lo público.

Dijeron las necesidades que en un tiempo futuro propiciarían nuevamente la organización política necesaria que se había dispersado en medio del "silencio feminista".

- Agradezco a la Vicerrectoría de Investigación y Desarrollo de la Universidad de Santiago de Chile el apoyo para realizar proyecto Dicyt "Escritoras de la Generación del cincuenta". Este artículo es producto de ese proyecto. 


\section{BIBLIOGRAFÍA}

Aguirre, Margarita, "Cuaderno de una muchacha muda", La Oveja roja, Buenos Aires, Editorial Sudamericana, 1974.

La culpa, Santiago de Chile, Editorial Zig-Zag, 1966.

Beauvoir, Simone de, La mujer rota, Buenos Aires, Editorial Sudamericana, 1974.

------- Memorias de una joven formal, Buenos Aires, Editorial Sudamericana, 1973.

El segundo sexo, Buenos Aires, Ediciones Siglo Veinte, 1965.

Bobbio, Norberto, El existencialismo, México, Fondo de Cultura Económica, 1997.

Bourdieu, Pierre, La dominación masculina, Barcelona, Editorial Anagrama, 2000.

La distinción. Crítica social del gusto, Madrid, Editorial Taurus, 1988.

Butler, Judith, Deshacer el género, Buenos Aires, Editorial Paidós, 2006.

Cixous, Hélène, La risa de la medusa: ensayos sobre la escritura, Barcelona, Editorial Anthropos, 1955.

Collier, Simon y William F. Sater, Historia de Chile 1808-1994, Cambridge, Cambridge University Press, traducción Milena Grass, 1998.

García-Corales, Guillermo y Margarita Aguirre, "Escritura del decir no dicho: cuerpo y secreto", Escritoras chilenas: novela y cuento, Patricia Rubio (ed.), Santiago, Editorial Cuarto propio, 1999.

Gertner, María Elena, La derrota, Santiago de Chile, Editorial Zig-Zag, 1964.

La mujer de sal, Santiago de Chile, Editorial Zig-Zag, 1964.

Islas en la ciudad, Editorial Zig-Zag, 1958.

------- Páramo salvaje, Santiago de Chile, Editorial Zig-Zag, 1957.

Godoy, Eduardo, La Generación del 50 en Chile. Historia de un movimiento literario, Santiago de Chile, Editorial La Noria, 1992.

Jara, Marta, Surazo, Santiago de Chile, Editorial Zig-Zag, 1962.

Kirkwood, Julieta, Ser política en Chile. Las feministas y los partidos, Santiago de Chile, Facultad Latinoamericana de Ciencias Sociales (FLACSO), 1986. 
Kofman, Sarah, El enigma de la mujer, Barcelona, Editorial Gedisa, 1982.

Lafourcade, Enrique, Cuentos de la generación del 50, Santiago de Chile, Editorial del Nuevo Extremo, Santiago, 1959.

Antología del nuevo cuento chileno, Santiago de Chile, Editorial Zig-Zag, 1954.

Rubio, Patricia, Escritoras chilenas: novela y cuento, Santiago de Chile, Editorial Cuarto Propio, 1999, pp. 309-329.

Sagan, Françoise, Buenos días tristeza, Barcelona, Tusquets Editores, 1955.

Sartre, Jean Paul, ¿Qué es literatura?, Buenos Aires, Editorial Losada, 1957.

Serrana, Elisa, Una, Santiago de Chile, Editorial Zig-Zag, 1964.

------ Chilena, casada, sin profesión, Santiago de Chile, Editorial Zig-Zag, 1963.

Valdivieso, Mercedes, La brecha, Santiago de Chile, Editorial Zig-Zag, 1961. 